\title{
AN EFFICIENT TECHNIQUE FOR RETINAL VESSEL SEGMENTATION AND DENOISING USING MODIFIED ISODATA AND CLAHE
}

\author{
KHAN BAHADAR KHAN ${ }^{* 1}$, AMIR ABDUl KHALIQ ${ }^{1}$, MUHAMMAD SHAHID ${ }^{2}$ \\ AND SHEROZ KHAN ${ }^{3}$ \\ ${ }^{I}$ Department of Electronic Engineering, International Islamic University, \\ Chairman Office, Sector H-10, Islamabad 44000, Pakistan. \\ ${ }^{2}$ Department of Electrical Engineering, Capital University of Science and Technology, \\ Kahuta Road, Zone-V, Islamabad 44000, Pakistan. \\ ${ }^{3}$ Department of Electrical and Computer Engineering, \\ Faculty of Engineering, International Islamic University Malaysia, \\ Jalan Gombak, 53100, Kuala Lumpur, Malaysia. \\ "corresponding author: kb.khattak@gmail.com \\ (Received: $7^{\text {th }}$ Jan. 2016; Accepted: 22 $2^{\text {nd }}$ Aug. 2016; Published on-line: 30 th Nov. 2016)
}

ABSTRACT: Retinal damage caused due to complications of diabetes is known as a Diabetic Retinopathy (DR). In this case, the vision is obscured due to damage of tiny retinal blood vessels. These tiny blood vessels may cause leakage that affect the vision and can lead to complete blindness. Identification of these new retinal vessels and their structure is an essential for analysis of DR. Automatic blood vessel segmentation plays a significant role to assist subsequent automatic methodologies that aid to such analysis. In literature, most authors have used computationally-hungry strong preprocessing steps followed by a simple thresholding and postprocessing steps. This paper proposed an arrangement of simple preprocessing steps that consist of Contrast Limited Adaptive Histogram Equalization (CLAHE) for contrast enhancement and a difference image of green channel from its Gaussian blur filtered image to remove local noise or geometrical objects. The proposed Modified Iterative Self Organizing Data Analysis Technique (MISODATA) has been used for segmentation of vessel and non-vessel pixels based on global and local thresholding. Finally, postprocessing steps have been applied using region properties (area, eccentricity) to eliminate the unwanted regions/segments, nonvessel pixels, and noise. A novel postprocessing steps are used to reject misclassified foreground pixels. The strategy has been tested on the openly accessible DRIVE (Digital Retinal Images for Vessel Extraction) and STARE (STructured Analysis of the REtina) databases. The average accuracy rates of 0.952 and 0.957 with average sensitivity rates 0.780 and 0.745 along with average specificity rates of 0.972 and 0.974 were obtained on DRIVE and STARE datasets, respectively. The performance of the proposed technique has been assessed comprehensively. The acquired accuracy, robustness, low complexity, and high efficiency make the method an efficient tool for an automatic retinal image analysis. The proposed technique perform well as compared to the existing strategies on the online available databases in term of accuracy, sensitivity, specificity, false positive rate, true positive rate, and area under receiver operating characteristic (ROC) curve.

ABSTRAK: Kerosakan retina yang disebabkan oleh komplikasi diabetes dikenali sebagai Diabetic Retinopathy (DR). Dalam kes ini, penglihatan menjadi kabur disebabkan oleh kerosakan saluran darah kecil retina. Saluran darah kecil boleh menyebabkan ketirisan yang menjejaskan penglihatan dan boleh mengakibatkan buta sepenuhnya. Mengenal pasti saluran retina baru dan struktur mereka adalah penting 
untuk DR analisis. Segmentasi saluran darah secara automatik memainkan peranan penting untuk membantu kaedah automatik berikutnya dan ini akan membantu analisis tersebut. Dalam literatur, kebanyakan orang telah menggunakan pengiraan langkah pra pemprosesan yang kuat diikuti dengan langkah ambang dan pos pemprosesan yang mudah. Kami mencadangkan susunan langkah pra pemprosesan mudah yang terdiri daripada Contrast Limited Adaptive Histogram Equalization (CLAHE) untuk mempertingkatkan kontras dan imej perbezaan saluran hijau daripada imej kabur Gaussian yang ditapis untuk membuang bunyi tempatan atau objek geometri. Modified Iterative Self Organizing Data Analysis Teknik (MISODATA) yang dicadangkan telah digunakan dalam membuat segmentasi piksel saluran dan bukan-saluran berdasarkan pengambangan global dan tempatan. Akhir sekali, langkah pos pemprosesan telah digunakan dengan menggunakan ciri-ciri kawasan (kawasan, kesipian) untuk menghapuskan wilayah / segmen, piksel bukan saluran dan bunyi bising yang tidak diingini. Kami telah menggunakan langkah pos pemprosesan baru untuk menolak piksel latar depan yang silap dikelaskan. Strategi ini telah diuji pada pangkalan data terbuka yang boleh diakses iaitu DRIVE (Digital Retinal Images for Vessel Extraction) dan Stare (STructured Analysis of the REtina). Kadar purata ketepatan 0.952 dan 0.957 dengan kadar purata sensitiviti 0.780 dan 0.745 bersama dengan kadar purata kekhususan 0.972 dan 0.974 telah diperolehi pada DRIVE dan Stare dataset, masing-masing. Prestasi teknik yang dicadangkan itu telah dinilai secara menyeluruh. Ketepatan yang diperolehi, kekukuhannya, kerumitan yang rendah dan kecekapan yang tinggi membuat kaedah ini alat yang berkesan untuk analisis imej retina automatik. Teknik yang dicadangkan menunjukkan prestasi yang baik berbanding dengan strategi tersedia ada pada pangkalan data dalam talian terkini dari segi ketepatan, kepekaan, kekhususan, kadar positif palsu, kadar positif benar dan kawasan di bawah lengkungan ciri operasi penerima (ROC).

KEYWORDS: vessel segmentation; fundus imaging; denoising; drive; stare; diabetic retinopathy

\section{INTRODUCTION}

Retinal blood vessel segmentation mainly focuses on the presence of the DR illness. Retinal anomalies are commonly caused by DR and hypertensive retinopathy, which are the significant reasons for visual deficiency and impairment these days. To analyze retinal variation, fundus imaging is progressively used as a part of the screening process. The retinal vein elements like microaneurysms, scratching, and narrowing have been connected to the systemic sickness of retinopathy in its earliest stages [1]. Visual deficiency usually caused by DR is irreversible even a recuperation procedure would not enable the patient to have earlier vision capacity. Consequently, the early identification of DR on a retinal image will save the patient from having irreversible visual impairment.

Segmentation is considered one of the fundamental stages in an image processing. It divides a digital image into numerous locales to make it easy for investigation. Analysis of the retinal veins can uncover early phases of cardiovascular ailment, hypertension, arteriosclerosis, diabetes, and stroke [2]. It alerts patients, enabling them to take anticipatory measures when the infection is in its initial stages. It is additionally used to recognize objects in an image of diverse nature. Object shape, edges, and correlation are three principle factors that impact segmentation of an object in the image. Object edges and object correlation is greatly influenced by noise or reproduction artifacts because they land on image attributes. Moreover, they are methodology dependent parameters. The advancement of image segmentation techniques are influenced by the knowledge of object shape, object correlation, and object edges. Segmentation methods attempt to identify 
edges and correlated areas in the images and consolidate shape data to confine the subsequent state segmentation more precisely [3].

Retinal images permit doctors to examine the retina and its inside segments, including the optic disk, vasculature, fovea, and so on [4]. Retinal veins provide data that is very helpful in a few applications such as restorative analysis and sorting of cardiovascular and ophthalmological ailments. The vessel segmentation can be utilized to portray hypertensive retinopathy along with the estimation of vessel width, which is used to analyze hypertension [5]. Symptoms of DR can be detected by changes in the vasculature distribution [4]. In addition, vessels are utilized to help laser surgeries [6] and can be used as landmark for image registration [7]. Retinal vessel segmentation is necessary for all of these operations.

In the typical scenario, trained experts do manual segmentation [2]. However, retinal blood vessel segmentation requires training and expertise to be manually segmented, which is also a tediously prolonged and exhausting task. It is usually acknowledged by medical experts that an automatic detection of vessels structure is the initial phase in the improvement of a computer-assisted indicative framework for ophthalmic problems. The performance can be examined by accuracy (Acc), specificity (Sp), sensitivity (Sn) and ROC curve on the distinctive databases like DRIVE and STARE. Therefore, a retinal vessels segmentation approach that is accurate and presents shorter computation time is necessary for denoising images in order to recognize DR and other ophthalmologic illnesses.

\section{RELATED WORK}

The automatic discovery of retinal vessels structure is an essential in the improvement of automated framework for the scrutiny of vasculature distribution. A mechanism, which can be utilized to help with the conclusion of DR and ought to consequently recognize all retinal image elements is necessary. The retinal image elements are optic disk, blood vessels, fovea, and all irregularities in the retinal image, which can be microaneurysms, cotton-wool spots, edema, and hemorrhages [8].

Automatic segmentation of retinal fundus images is considered one of the basic steps of vessel extraction from background. Bad quality retinal images having some noise, variable width of vessels, and changes of brightness which make segmentation a challenging task. Vessel structure in retinal fundus images can be extracted by numerous vessel detection techniques that have already been suggested in literature [8,9]. These techniques can be comprehensively partitioned into supervised and unsupervised classifications. Supervised strategies segregate between vessel and non-vessel pixels using pixel-based attribute vectors to train a classifier, while unsupervised techniques do not utilize classifiers but depend on thresholding filter responses to reduce false responses to online edges [10].

\subsection{Supervised Methods}

The requirement for this methodology is that an arrangement of important distinguishing features must be extracted for training from good quality images. For example, Ricci and Perfetti [11] utilized Support Vector Machine (SVM) to learn a feature vector extraction. Becker et al. [12], presented supervised method to learn feature vector recognition utilizing gradient boosting framework. Neural network and Principal Component Analysis (PCA) concepts were utilized for pixel classification and edge detection respectively by Sinthanayothin et al. [13]. Green plane was used for feature 
vector extraction of each pixel and $k$-Nearest Neighbor $(\mathrm{kNN})$ was utilized to classify vessel pixels [14]. Staal et al. [15], proposed a primitive-based supervised method to extract a feature vector for each pixel based on characteristics of the segments and the line components. The feature vectors were grouped utilizing a $\mathrm{kNN}$ and successive forward feature selection techniques. Soares et al. [16], used the pixel's intensity to extract a feature vector and two-dimensional (2D) Gabor wavelet transform was used to separate true positive and false positive pixels with the final segmentation by a Gaussian Mixture Model (GMM) classifier. In [17], various concavity modeling approaches were used for blood vessel segmentation. Bright lesions were handled by techniques utilizing differentiable concavity measures where dark scrapes were removed by line-shape concavity measures and random noise was managed by locally normalized concavity measures. These concavity measures were consolidated together as per their statistical distributions to distinguish vessel and non-vessel pixels. Joshi et al. [18], presented an automated technique for detection and segregation of retinal vessel structure using a graph search method.

\subsection{Unsupervised Methods}

In comparison, unsupervised techniques perform the segmentation of retinal vessels without utilizing trained information, or any classification methods. This class incorporates most segmentation methods in the literature. For instance, in [19], the authors proposed an active contour model to detect vessel borders and sustain vessel width consistency. Zhang et al. [20], learned a multi-dimensional feature vector by morphological operation, pixel clustering by Self Organizing Map (SOM), and classification of vessel and non-vessel pixels through Otsu's method. Lupaşcu and Tegolo [21], utilized SOM and a k-means clustering algorithm for training and division of map units. A hill-climbing strategy has been used for postprocessing of the segmented image. Chaudhuri et al. [22], presented a 2D matched filter using a Gaussian-shaped curve. They achieved very low average accuracy because of the low identification of retinal vessels. Hoover et al. [23], used local and global vessel characteristics collectively by applying a thresholding and matched filter response (MFR) to segment the vessel system. In [24], second order derivative Gaussian MFR has been used to find the centroid and vessel diameter, and an extended Kalman filter for excellent predication of subsequent vessel regions. Mendonca and Campilho [25], used outputs of four differential filters with morphological operators for centerline detection, vessel features and morphological characteristics for filling vessel structures. Zana and Klein [26], employed cross-curvature evaluation and morphological filters together to segment vessel structure. However, their presented method was inadequate to segment thinner vessels. In [27], retinal blood vessel segmentation has been performed by a multiscale feature extraction and region growing algorithm. Matinez-Perez et al. [28] utilized first and second-spatial derivatives of the image intensity that give details of vessel structure to control the inherent issue of contrast variations in these images. This approach additionally empowers the analysis of vessels of variable lengths, widths and orientations. Fraz et al. [29], used centerline detection techniques and morphological bit plane slicing for retinal vessel segmentation. Bankhead et al. [30], utilized wavelets and edge location refinement method for retinal vessel segmentation. Related works are summarized in Table 1. 
Table 1: Classification of retinal vessel segmentation techniques.

\begin{tabular}{|c|c|c|c|c|}
\hline Method & year & $\begin{array}{c}\text { Proposed } \\
\text { methodology }\end{array}$ & $\begin{array}{l}\text { Performance } \\
\text { parameters }\end{array}$ & Limitations \\
\hline $\begin{array}{l}\text { Ricci et al. } \\
\text { [11] }\end{array}$ & 2007 & $\begin{array}{l}\text { Line operators and } \\
\text { SVM }\end{array}$ & Acc and AUC & $\begin{array}{l}\text { High false positive rate and } \\
\text { inadequate for noise removal. }\end{array}$ \\
\hline $\begin{array}{l}\text { Sinthanayothin } \\
\text { et al. [13] }\end{array}$ & 1999 & $\begin{array}{l}\text { PCA and neural } \\
\text { network }\end{array}$ & Sn and $\mathrm{Sp}$ & $\begin{array}{l}\text { Inadequate for geometrical object } \\
\text { e.g. fovea removal. Missed tiny } \\
\text { blood vessels. }\end{array}$ \\
\hline $\begin{array}{l}\text { Niemeijer et al. } \\
{[14]}\end{array}$ & 2004 & $\begin{array}{l}\text { Pixel classification } \\
\text { based on kNN- } \\
\text { classifier }\end{array}$ & Acc and AUC & $\begin{array}{l}\text { Under-segmentation around the } \\
\text { boundary of the optic disk. Smaller } \\
\text { vessels not detected properly. }\end{array}$ \\
\hline Staal et al. [15] & 2004 & $\begin{array}{l}\text { Image ridges and } \\
\mathrm{kNN} \text {-classifier }\end{array}$ & Acc and AUC & $\begin{array}{c}\text { False detection of vessels at } \\
\text { boundaries, optic disk and for } \\
\text { pathological images. }\end{array}$ \\
\hline $\begin{array}{l}\text { Soares et al. } \\
{[16]}\end{array}$ & 2006 & $\begin{array}{l}\text { 2D Gabor } \\
\text { wavelet transform and } \\
\text { GMM classifier }\end{array}$ & Acc and AUC & $\begin{array}{l}\text { Incorrect recognition of noise and } \\
\text { other artifacts. Unable to detect some } \\
\text { of the thinnest vessels. Disregard } \\
\text { useful information from shapes and } \\
\text { structures present in the image. }\end{array}$ \\
\hline Lam et al. [17] & 2010 & $\begin{array}{l}\text { Multiconcavity } \\
\text { modeling }\end{array}$ & Acc and AUC & Lesion detection problem. \\
\hline $\begin{array}{l}\text { Al-Diri et al. } \\
{[19]}\end{array}$ & 2009 & $\begin{array}{l}\text { Ribbon of twin active } \\
\text { contour model }\end{array}$ & Sn and $\mathrm{Sp}$ & $\begin{array}{l}\text { Failed in edge identification and to } \\
\text { accurately detect overlaps or closely } \\
\text { parallel vessels. }\end{array}$ \\
\hline $\begin{array}{l}\text { Zhang et al. } \\
\text { [20] }\end{array}$ & 2015 & $\begin{array}{l}\text { Morphological } \\
\text { operation and SOM }\end{array}$ & Acc & $\begin{array}{l}\text { Need to test on STARE dataset and } \\
\text { also must compute its Sp and AUC. }\end{array}$ \\
\hline $\begin{array}{l}\text { Lupaşcu et al. } \\
{[21]}\end{array}$ & 2010 & $\begin{array}{l}\text { SOM and k-means } \\
\text { clustering }\end{array}$ & Sn, Sp and Acc & Greater time complexity. \\
\hline $\begin{array}{l}\text { Chaudhuri et } \\
\text { al. [22] }\end{array}$ & 1989 & $\begin{array}{l}\text { 2D Gaussian Matched } \\
\text { Filter (MF) }\end{array}$ & Acc and AUC & $\begin{array}{l}\text { False detection of edge on different } \\
\text { retinal abnormal images. }\end{array}$ \\
\hline $\begin{array}{l}\text { Hoover et al. } \\
\text { [23] }\end{array}$ & 2000 & $\begin{array}{c}\text { Threshold probing and } \\
\text { MF }\end{array}$ & Sn, Sp and Acc & $\begin{array}{l}\text { Improvement in the vessel detection } \\
\text { rate required. }\end{array}$ \\
\hline $\begin{array}{l}\text { Mendonca et } \\
\text { al. [25] }\end{array}$ & 2006 & $\begin{array}{l}\text { Detection of } \\
\text { centerlines and } \\
\text { morphological } \\
\text { reconstruction }\end{array}$ & Acc and AUC & $\begin{array}{l}\text { Under-segmentation of several vessel } \\
\text { regions. False detection of vessels. } \\
\text { Fractional, or complete, omission of } \\
\text { thin vessel segments. }\end{array}$ \\
\hline $\begin{array}{l}\text { Zana and Klein } \\
{[26]}\end{array}$ & 2001 & $\begin{array}{c}\text { Mathematical } \\
\text { morphology and } \\
\text { curvature evaluation }\end{array}$ & $\begin{array}{l}\text { TPR, Acc and } \\
\text { AUC }\end{array}$ & $\begin{array}{l}\text { It generates linked linear structures } \\
\text { that are uncontaminated but not } \\
\text { always connected to each other. Tiny } \\
\text { vessels of low contrast are } \\
\text { incompletely identified. }\end{array}$ \\
\hline $\begin{array}{l}\text { Palomera- } \\
\text { Perez et al. } \\
\quad[27]\end{array}$ & 2010 & $\begin{array}{l}\text { Region growing } \\
\text { technique and parallel } \\
\text { multiscale } \\
\text { implementation }\end{array}$ & $\begin{array}{l}\text { TPR, FPR and } \\
\text { Acc }\end{array}$ & $\begin{array}{l}\text { Not suitable for high resolution } \\
\text { images. }\end{array}$ \\
\hline $\begin{array}{l}\text { Martinez-Perez } \\
\text { et al. [28] }\end{array}$ & 2007 & $\begin{array}{l}\text { Multiscale feature } \\
\text { extraction, two } \\
\text { geometric properties } \\
\text { and region growing }\end{array}$ & $\begin{array}{l}\text { TPR, FPR and } \\
\text { Acc }\end{array}$ & $\begin{array}{l}\text { Incapable to remove geometrical } \\
\text { objects e.g. hemorrhages, } \\
\text { microaneurysms in mixture with the } \\
\text { detection of blood vessels. }\end{array}$ \\
\hline Fraz et al. [29] & 2011 & $\begin{array}{l}\text { Bit planes and } \\
\text { centerline detection }\end{array}$ & $\begin{array}{l}\text { TPR, FPR, Sp, } \\
\text { Acc and } \mathrm{Sn}\end{array}$ & $\begin{array}{l}\text { Not appropriate for pathological and } \\
\text { those retinal images where arterioles } \\
\text { show clear light reflexes e.g. in } \\
\text { images of younger applicants. }\end{array}$ \\
\hline $\begin{array}{l}\text { Bankhead et al. } \\
\text { [30] }\end{array}$ & 2012 & $\begin{array}{l}\text { Wavelets and edge } \\
\text { location refinement }\end{array}$ & $\begin{array}{l}\text { TPR, FPR and } \\
\text { Acc }\end{array}$ & $\begin{array}{l}\text { If the image contrast diminishes then } \\
\text { proper zero-crossings may not be } \\
\text { detected at all areas along the vessel. }\end{array}$ \\
\hline
\end{tabular}

Performance measures: Sn- sensitivity, Sp - specificity, Acc - accuracy, AUC - area under curve. FPR false positive rate. TPR - true positive rate. 
The work in this paper proposes a fast and precise unsupervised technique to identify and measure retinal vessels. The proposed method consists of CLAHE [31], modified ISODATA [32] and a novel postprocessing steps. CLAHE has been utilized to enhance the local contrast and prevent the uncorrelated areas in retinal image analysis. Further, MISODATA technique has been applied to find the global threshold of the entire image which is compared with the individual local threshold of each segment in order to detect vessels. Finally, postprocessing steps have been applied to obtain the resulting segmented image. The proposed method is demonstrated to be equipped for acquiring an enhanced state of accuracy and low estimation error both for low and high resolution images, as compared to other blood vessel segmentation techniques.

\section{PROPOSED TECHNIQUE}

Retinal images are usually corrupted with noise due to illumination and contrast variation that make challenging the extraction of a vessel map. An efficient preprocessing method is required to fix this problem. This section illustrates distinctive preprocessing steps, thresholding techniques, and postprocessing steps to enhance and segment the retinal blood vessels. The flow diagram of the proposed technique is shown in Fig. 1.

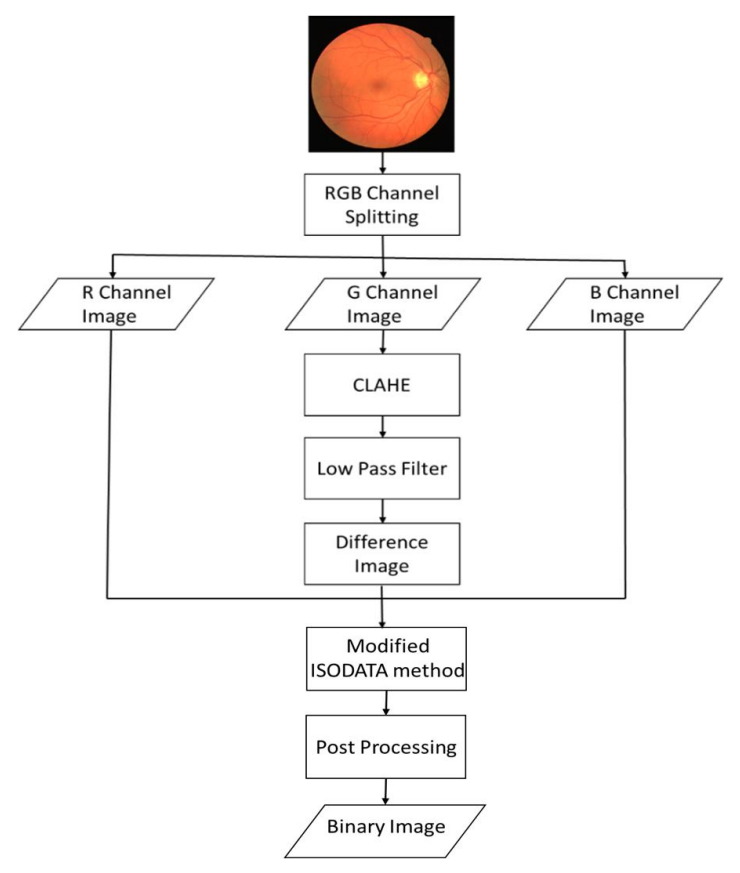

Fig. 1: Flowchart of the proposed method.

- Input the RGB retinal image and extract the green channel of an input image.

- Image localized contrast enhancement through CLAHE.

- Take difference image of average filtered image and input image for removal of abnormalities/geometrical objects, e.g. optic disc, macula, and bigger structures. For an average filter, selected kernel size is more than vessel's diameter size. This also makes the edges more prominent than the background.

- Segmentation based on the implementation of MISODATA.

- Execution of postprocessing using raster to vector transformation and then computation of area and eccentricity to scale down noise and non-vessel regions in order to obtain final binary retinal image. 


\subsection{Contrast Limited Adaptive Histogram Equalization (CLAHE)}

In retinal images, it is difficult to differentiate between intensity variations of vessel and non-vessel segments. In order to enhance the algorithm result, intensity transformation is applied to increase the intensity gap between vessel and non-vessel pixels. Contrast enhancement can be achieved in different ways e.g. Histogram Equalization (HE) [33], adjustment, equalization, contrast stretching [33], and local Adaptive Histogram Equalization (AHE) [34].

AHE is a well-known contrast enhancement strategy for medical and natural images proposed by Pizer [34]. In its fundamental form, the histogram equalization of an image, each pixel is mapped on its surrounding pixels (its contextual region). This method is slow, and under particular conditions the enhanced image has unwanted components, as compared to its other counterparts. An advanced version of AHE known as CLAHE [31] is comparatively fast with better localized contrast results. CLAHE was initially designed for improvement of low contrast medical images [35]. CLAHE is implemented in the following way:

- Specify a square neighborhood (block) to estimate the histogram in the local block.

- Generate the transformation function by histogram equalization or specification and perform the gray level mapping for each pixel.

- Each time, the histogram can be updated without re-computing the histogram over all pixels in the new block.

- Move the center of the block to an adjacent pixel position and repeat the process.

The discrete approximation of the transformation function $\mathrm{T}$ for histogram equalization [33] is given by:

$$
\mathrm{s}_{\mathrm{k}}=\mathrm{T}\left(\mathrm{r}_{\mathrm{k}}\right)=\sum_{\mathrm{j}=0}^{\mathrm{k}} \mathrm{p}_{\mathrm{r}}\left(\mathrm{r}_{\mathrm{j}}\right)
$$

For $0 \leq k \leq L-1, p_{r}\left(r_{j}\right)=\frac{n_{j}}{n}$ for $j=0, \ldots \ldots ., L-1$ and $n=\sum_{j=0}^{L-1} n_{j}$ where $n_{j}$ shows the number of pixels with gray levels $r_{j}$ and $n$ is the total number of pixels. $L$ represents gray levels. CLAHE differs from normal AHE in constraining the contrast enhancement. CLAHE uses a user-defined value called the clip limit to constrain enhancement by clipping the histogram [31]. The clipping level specifies the noise level to be smoothened and contrast level to be enhanced.

\subsection{Modified Iterative Self Organizing Data Analysis Technique (MISODATA)}

Before using MISODATA, a low pass filter is used for noise removal and computing the difference image. MISODATA is a thresholding method that automatically determines the optimal threshold value instead of imposing a manual threshold [32]. In general, MISODATA initially computes the global mean of an image that can be used as a global threshold (GT). Secondly, using GT, all pixels were classified into two clusters called Mean Above Threshold $\left(\mathrm{MAT}_{\mathrm{G}}\right)$ and Mean Below Threshold $\left(\mathrm{MBT}_{\mathrm{G}}\right)$. In the third step, the new cluster mean vectors were computed based on all the pixels in each individual cluster. The second and third steps are repeated until the average mean in the third step becomes equal to global mean.

Besides calculating GT, the image is divided into square or rectangular local patches and each local patch is used to calculate local mean to set as a local threshold (LT). Each patch is further classified into two clusters with a reference to a LT. Using LT, all pixels 
were classified into two levels having value greater than LT called Mean Above Threshold $\left(\mathrm{MAT}_{\mathrm{L}}\right)$ and having value lower than LT called Mean Below Threshold $\left(\mathrm{MBT}_{\mathrm{L}}\right) . \mathrm{MAT}_{\mathrm{L}}$ and $\mathrm{MBT}_{\mathrm{L}}$ have been computed based on all the pixels in each individual cluster. The iterative method is repeated until the local threshold became equal to the average mean threshold of both clusters. Further, GT is compared with LT; in case LT >GT and has to be updated by $\mathrm{LT}=\mathrm{GT}$. If $\mathrm{LT} \ll \mathrm{GT}$ the $\mathrm{LT}=\mathrm{GT}$-threshold value is updated. In this way, MISODATA is implemented for classification of vessel and non-vessel pixels. Further, the postprocessing technique has been applied to obtain a final segmented image. The block diagram for the presented MISODATA is shown in Fig. 2.

The proposed MISODATA visual and quantitative results have been compared with ISODATA [32], Fuzzy C-Means (FCM) also known as fuzzy ISODATA [40] and the $k$ means clustering method [41]. Figure 3 shows that the proposed MISODATA produced good visual results compared to FCM and $k$-means methods on the DRIVE [36] dataset. The proposed MISODATA also extracts thin vessels along with the wide vessels. Its quantitative results are tabulated in Table 2, which clearly indicates that the proposed method shows superior performance to other methods. The drawback of basic ISODATA is that it fails sometimes to find an optimal threshold while FCM suffers from high computation complexity. The disadvantage of the $k$-means method is that the means of clusters are calculated once, then remain unchanged. The proposed MISODATA takes a little more computation time than the basic ISODATA algorithm because it has been applied once locally and then globally on the entire image.

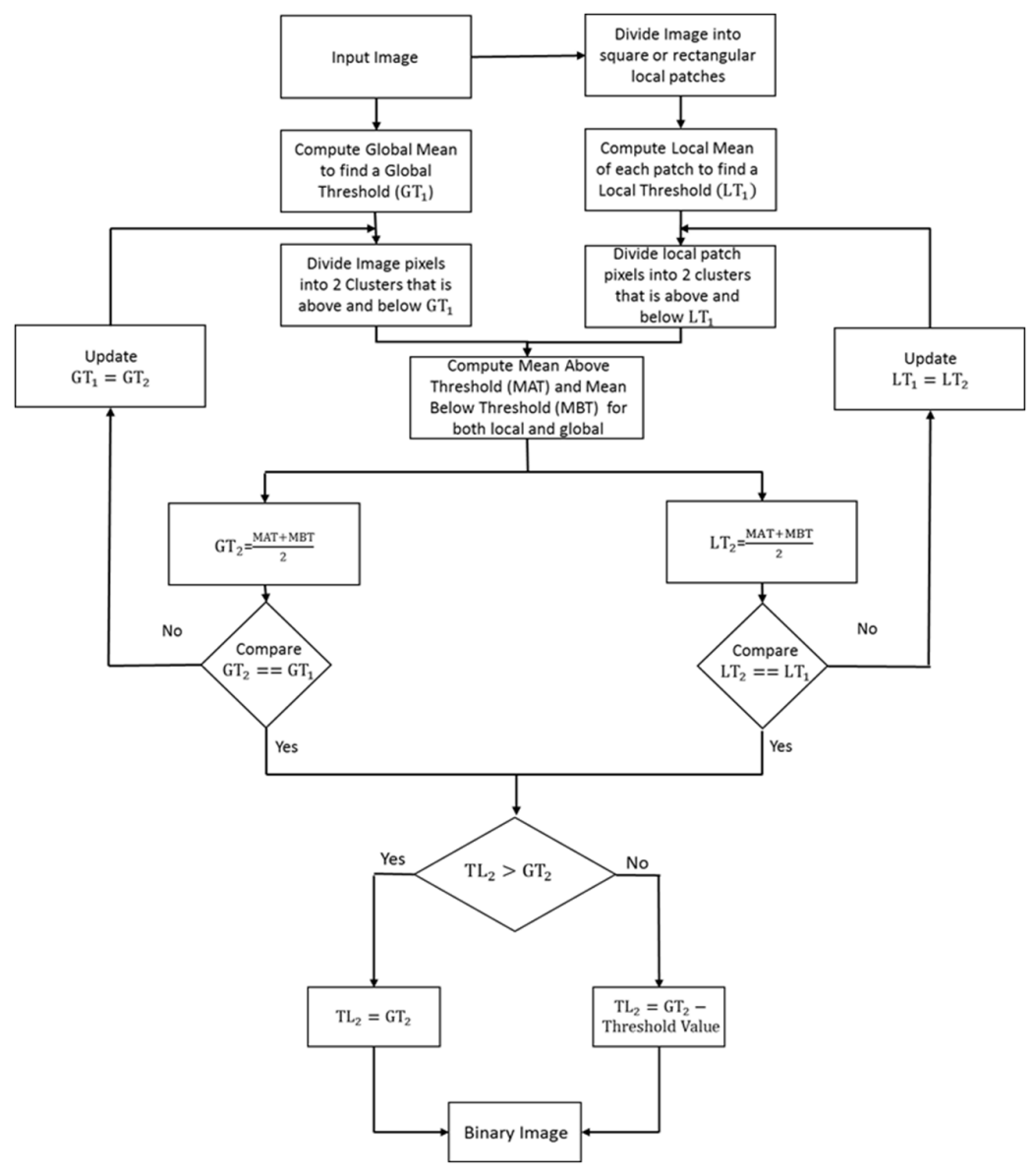

Fig. 2: MISODATA block diagram. 


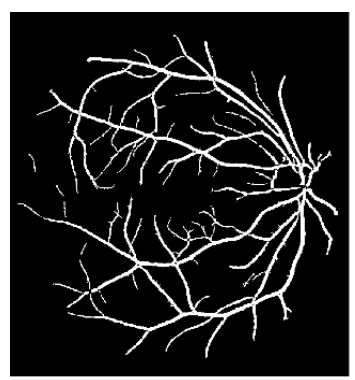

(a)

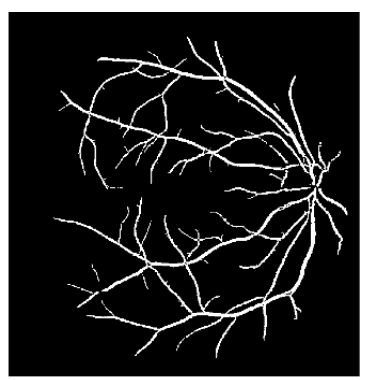

(b)

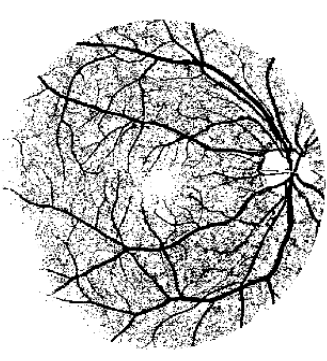

(c)

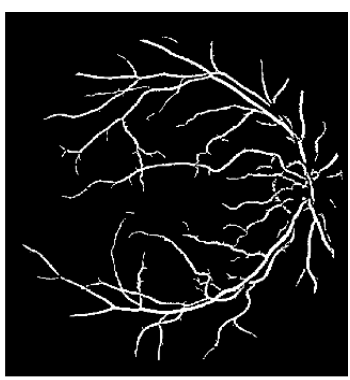

(d)

Fig. 3: Visual results comparison of MISODATA with other clustering methods. (a) MISODATA segmented image. (b) ISODATA image. (c) FCM image. (d) k-means method image.

Table 2: Performance comparison of MISODATA with other clustering methods.

\begin{tabular}{lllll}
\hline \multirow{2}{*}{ Method } & \multicolumn{4}{c}{ DRIVE } \\
\cline { 2 - 5 } & Acc & Sn & Sp & AUC \\
\hline ISODATA [32] & 0.957 & 0.674 & 0.985 & 0.829 \\
FCM [40] & 0.913 & 0.751 & 0.935 & 0.843 \\
k-means [41] & 0.959 & 0.716 & 0.980 & 0.848 \\
Proposed MISODATA & $\mathbf{0 . 9 5 2}$ & $\mathbf{0 . 7 8 0}$ & $\mathbf{0 . 9 7 2}$ & $\mathbf{0 . 8 7 6}$ \\
\hline
\end{tabular}

\subsection{Postprocessing: Region Properties Based Non-Vessels Rejection}

The postprocessing consists of a number of distinct steps as shown in Fig. 4. In the first step, the binary image produced by MISODATA has been labeled, each separate foreground pixel has been assigned specific number. The region properties, like eccentricity and area of each distinct patch have been calculated. The vessels patches are elongated and have a high area and eccentricity almost equal to one. Based on these properties, the noisy parts are rejected. Region properties are used to scale down the unwanted region, non-vessel pixels, and noise. The first stage in the raster-to-vector conversion process is usually an attempt to remove, or at least minimize the noise. If binarization and noise removal are successful, each line in the original drawing will generate an elongated region of black pixels in the binary image. The next step is to reduce each such region to a one-pixel wide string of pixel locations which is achieved by finding the center line of each region (skeletonisation). Noise can appear in a binary image in several forms, e.g. separated pixels of the opposite sign in an object or background regions, often known as salt-and-pepper noise, small holes in objects and/or small spots on background areas, distinct lines merging and single lines splitting. Skeletons can be achieved either by "thinning", an iterative process of removing black pixels until only a unit-width string remains, or via a "medial axis transform". Thinning produces a "thinned" binary image in which object pixels lie upon the skeleton of the original object. The medial axis transform produces a "medial axis", the locus of the centers of a set of maximal discs laid over the object. This is equivalent to the locus of local maxima of some distance measure.

Visual results of retinal blood vessel segmentation with the major processing steps of the proposed method using the DRIVE and the STARE databases are shown in Fig. 5 and Fig. 6, respectively. 


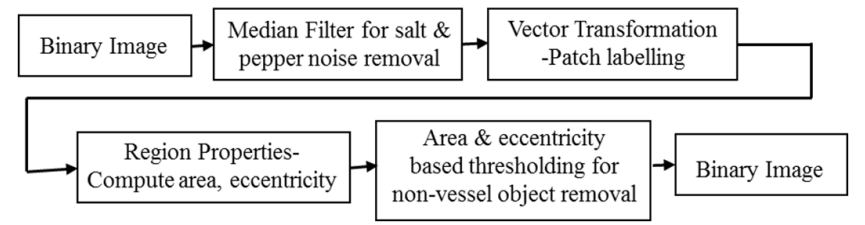

Fig. 4: Postprocessing raster-to-vector transformation steps.

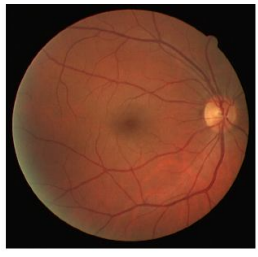

(a)

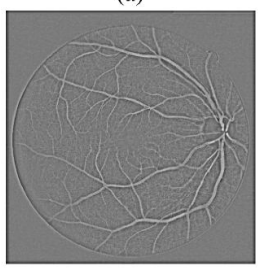

(e)

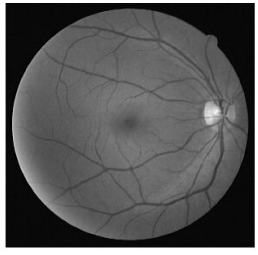

(b)

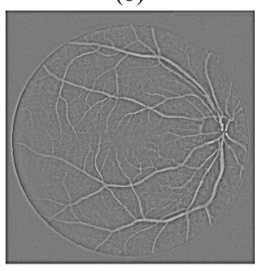

(f)

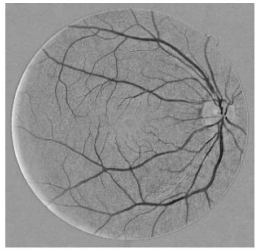

(c)

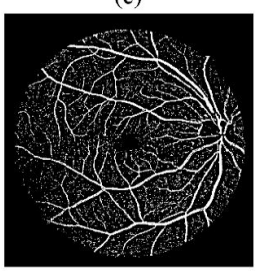

(g)

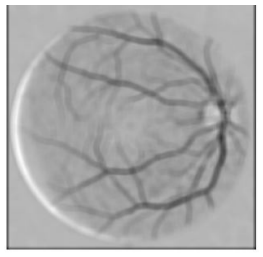

(d)

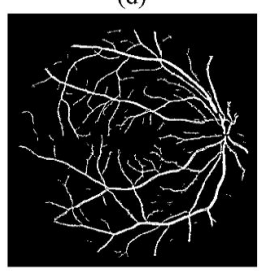

(h)

Fig. 5: Main processing steps of the proposed technique for retinal blood vessel segmentation. (a) RGB image from DRIVE database. (b) Extraction of Green channel for later processing. (c) CLAHE used for contract enhancement. (d) Low pass Gaussian blur filter for noise removal. (e) Difference image for background elimination. (f) Masking to remove unwanted effects. (g) MISODATA for vessel and non-vessel pixels classification. (h) Postprocessing steps for scaling down the unwanted regions, non-vessel pixels, noise, and removing erroneously detected segments.

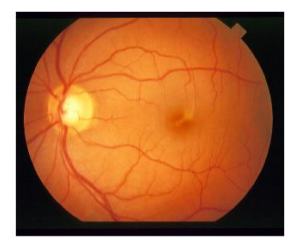

(a)

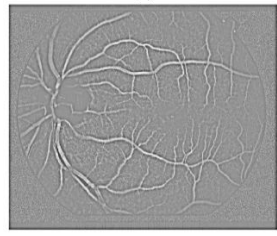

(e)

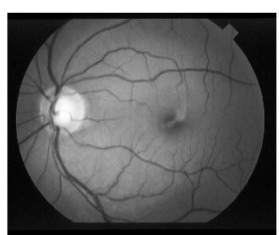

(b)

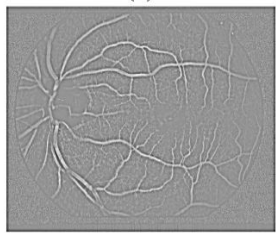

(f)

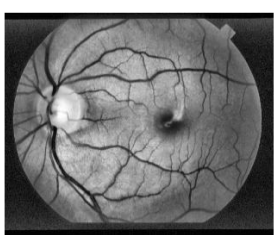

(c)

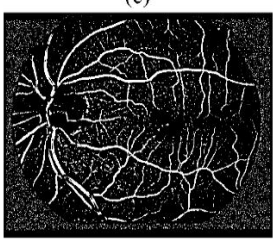

(g)

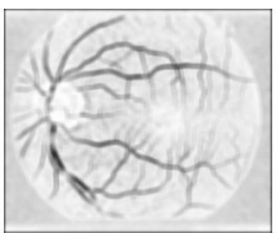

(d)

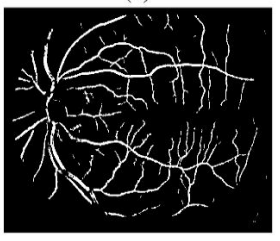

(h)

Fig. 6: Major processing steps proposed technique for retinal blood vessel segmentation. (a) RGB image from STARE database (b) Extraction of Green channel for later processing

(c) CLAHE used for contract enhancement (d) Low pass Gaussian blur filter for noise removal (e) Difference image for background elimination (f) Masking to remove unwanted effects (g) MISODATA for vessel and non-vessel pixels classification (h) Postprocessing steps for scaling down the unwanted regions, non-vessel pixels, noise and removing erroneously detected segments. 


\section{EXPERIMENTAL RESULTS AND COMPARISONS}

The efficiency of the presented framework has been assessed and compared with the latest techniques to evaluate its performance on two openly available the DRIVE [36] and the STARE [37] datasets. The STARE and the DRIVE datasets comprise 20 and 40 retinal images, respectively. Both databases are isolated into two sets: a training set and a test set. In each dataset, the segmentation of the first observer has been utilized as a ground truth for assessment while the performance of the second observer has been used as a benchmark for comparison. These databases consist of manual segmentation of experts as a gold standard. Based on these gold standards, the accuracy, sensitivity, and specificity of each method have been calculated. The performance measure for segmentation of retinal vessel structure is given in Table 3 .

Table 3: Performance measures for segmentation of retinal vessel structure.

\begin{tabular}{ll}
\hline Metrics & Explanation \\
\hline TPR & TP/vessel pixel count \\
FPR & FP/non-vessel pixel count \\
Sensitivity(Sn) & TPR or TP/(TP+FN) \\
Specificity $(\mathrm{Sp})$ & 1-FPR or TN/(TN+FP) \\
Accuracy(Acc) & $(\mathrm{TP}+\mathrm{TN}) /(\mathrm{TP}+\mathrm{FP}+\mathrm{TN}+\mathrm{FN})$ \\
AUC & $\mathrm{Sn}+\mathrm{Sp} / 2$ \\
\hline
\end{tabular}

TP, TN, FP and FN show the true positive (accurately detected vessel pixels), true negative (accurately detected background pixels), false positive (wrongly detected vessel pixels), and false negative (wrongly detected background pixels), respectively. The area under a receiver operating characteristic (ROC) curve, also known as area under the curve (AUC), has the ability to reflect the trade-offs between the sensitivity and specificity. Note that an AUC of 0.50 implies that the classification is equivalent to a pure random guess, and an AUC of 1.0 implies that the classifier recognizes class examples perfectly.

\subsection{Accuracy}

The metrics calculated on the two public databases to analyze the efficiency of the algorithms are given in Table 4. The parameters of the presented technique are set to deliver the highest possible accuracy. This can result decreased in a sensitivity to gain specificity in order to increase the overall accuracy. Experimental results demonstrated that the proposed method is an efficient for segmentation of retinal blood vessels. The effectiveness of proposed method has been validated by comparison of the performance results with other existing methods on two openly available DRIVE and STARE datasets.

The proposed method reaches a highest accuracy compared to other methods as shown in Table 4, which presents the performance comparison on the DRIVE and the STARE datasets. The results of Mendonça and Campilho [25], Martinez-Perez et al. [28], Palomera-Perez et al. [27], Zhang et al. [20], Al-Diri et al. [19], Niemeijer et al. [14], Lam et al. [17], Bankhead et al. [30] and Fraz et al. [29] are acquired from their original papers while Soares et al. [16] and Staal et al. [15] are obtained from their websites utilizing the segmented images. Chaudhuri et al. [22] and Zana and Klein [26] techniques results were executed by Niemeijer et al. [14]. The databases contain a second manual segmentation made by a human observer, which are also included in the comparison. The exploratory results on the DRIVE and the STARE dataset authenticate that the proposed technique is more efficient than the other mentioned frameworks. Fig. 7 and Fig. 8 show visual 
inspection of proposed retinal vessels segmentation method using the DRIVE and the STARE databases, respectively.

Table 4: Performance comparison for various methods.

\begin{tabular}{llcccccc}
\hline \multirow{2}{*}{ Method Type } & \multirow{2}{*}{ Method } & DRIVE & \multicolumn{5}{c}{ STARE } \\
\cline { 2 - 7 } Unsupervised & Acc & Sn & Sp & Acc & Sn & Sp \\
& Human observer & 0.947 & 0.776 & 0.972 & 0.935 & 0.895 & 0.939 \\
& Mendonça and Campilho [25] & 0.945 & 0.734 & 0.976 & 0.944 & 0.699 & 0.973 \\
& Martinez-Perez et al. [28] & 0.934 & 0.725 & 0.965 & 0.941 & 0.751 & 0.955 \\
& Palomera-Perez et al. [27] & 0.922 & 0.660 & 0.961 & 0.924 & 0.779 & 0.940 \\
& Zhang et al. [20] & 0.938 & 0.712 & 0.973 & 0.948 & 0.717 & 0.975 \\
& Fraz et al. [29] & 0.943 & 0.715 & 0.976 & 0.944 & 0.731 & 0.968 \\
& Bankhead et al. [30] & 0.937 & 0.703 & 0.971 & 0.932 & 0.758 & 0.950 \\
& Chaudhuri et al. [22] & 0.877 & 0.336 & - & - & - & - \\
& Zana and Klein [26] & 0.938 & 0.697 & - & - & - & - \\
& Al-Diri et al. [19] & - & 0.728 & 0.955 & - & 0.752 & 0.968 \\
& Proposed & $\mathbf{0 . 9 5 2}$ & $\mathbf{0 . 7 8 0}$ & $\mathbf{0 . 9 7 2}$ & $\mathbf{0 . 9 5 7}$ & $\mathbf{0 . 7 4 5}$ & $\mathbf{0 . 9 7 4}$ \\
& Niemeijer et al. [14] & 0.942 & 0.714 & - & - & - & - \\
& Staal et al. [15] & 0.944 & 0.719 & 0.977 & 0.952 & 0.697 & 0.981 \\
& Soares et al. [16] & 0.946 & 0.723 & 0.976 & 0.948 & 0.723 & 0.976 \\
& B.S.Y. Lam et al. [17] & 0.947 & - & - & 0.957 & - & - \\
& Marin et al. [39] & 0.945 & 0.706 & 0.980 & 0.952 & 0.694 & 0.981 \\
\hline
\end{tabular}

"_." Shows that this content was not available.

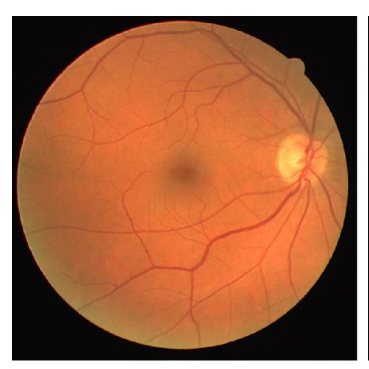

(a)

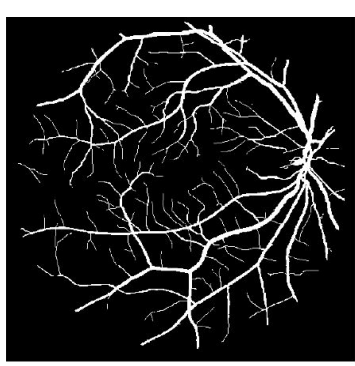

(b)

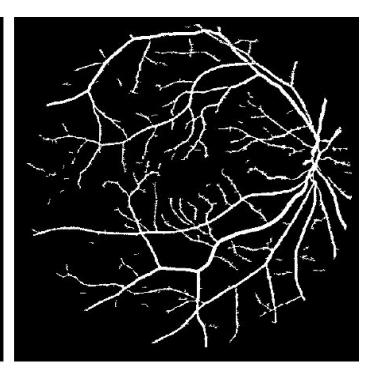

(c)

Fig. 7: Visual results of vessel segmentation using the DRIVE database. (a) RGB retinal input image (b) Manual segmented image (c) Proposed method final image.

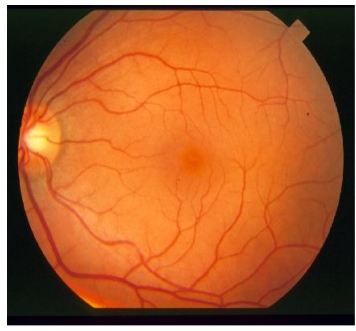

(a)

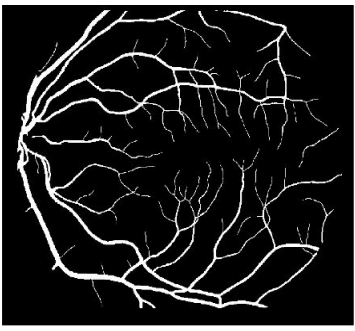

(b)

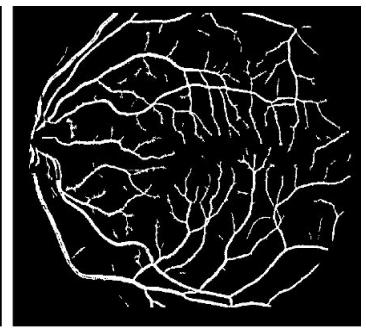

(c)

Fig. 8: Visual results of vessel segmentation using the STARE database. (a) RGB retinal input image (b) Manual segmented image (c) Proposed method final image.

One important factor of the proposed method is to suppress unwanted regions, nonvessel pixels and noise that will frequently show up in the anomalous retinal images 
through postprocessing steps. In order to assess the performance of the proposed technique, in such pathological cases, the results are analyzed by various techniques on the normal and abnormal images in the DRIVE and the STARE databases shown in Table 5. Experimental results emphasized that for abnormal cases, the proposed technique achieves much better efficiency than Chaudhuri et al. [22], Mendonça and Campilho [25], Hoover et al. [23] and it performs slightly better than Soares et al. [16]. Fig. 9 and Fig. 10 show visual results for abnormal retinal images of DRIVE and STARE databases, respectively.

Table 5: Segmentation results comparison of the proposed method with various segmentation methods for normal versus abnormal cases

\begin{tabular}{llccc}
\hline Image Type & Method & TPR & FPR & Acc \\
\hline Normal & Human observer & 0.9646 & 0.0764 & 0.9283 \\
& Chaudhuri et al. [22] & 0.7335 & 0.0218 & 0.9486 \\
& Mendonça and Campilho [25] & 0.7258 & 0.0209 & 0.9492 \\
& Hoover et al. [23] & 0.6766 & 0.0338 & 0.9324 \\
& Soares et al. [16] & 0.7554 & 0.0188 & 0.9542 \\
& Proposed & $\mathbf{0 . 8 5 4 7}$ & $\mathbf{0 . 0 1 9 1}$ & $\mathbf{0 . 9 7 4}$ \\
Abnormal & Human observer & 0.8252 & 0.0456 & 0.9425 \\
& Chaudhuri et al. [22] & 0.5881 & 0.0384 & 0.9276 \\
& Mendonca and Campilho [25] & 0.6733 & 0.0331 & 0.9388 \\
& Hoover et al. [23] & 0.6736 & 0.0528 & 0.9211 \\
& Soares et al. [16] & 0.6869 & 0.0318 & 0.9416 \\
& Proposed & $\mathbf{0 . 8 5 1 0}$ & $\mathbf{0 . 0 5 5 2}$ & $\mathbf{0 . 9 4 5 1}$ \\
\hline
\end{tabular}

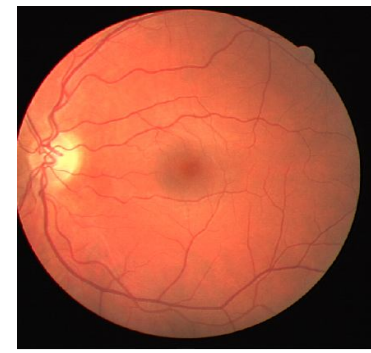

(a)

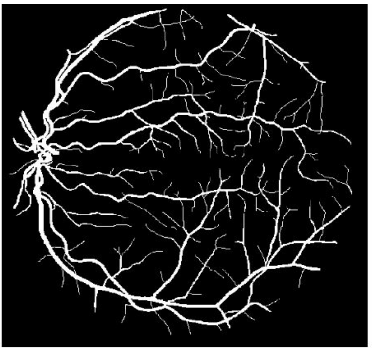

(b)

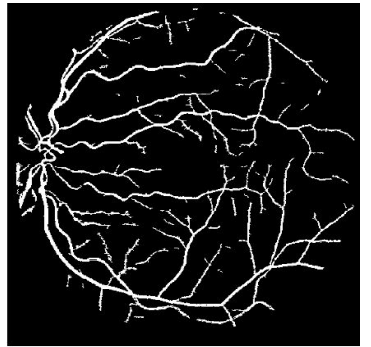

(c)

Fig. 9: Visual segmentation results of an abnormal image of the DRIVE database (a) RGB retinal input image (b) Manual segmented image (c) Proposed method final image.

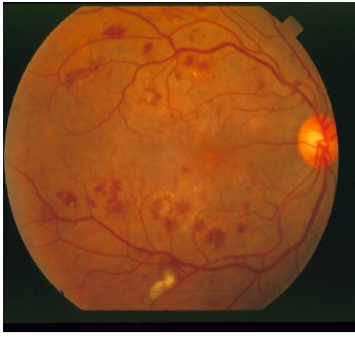

(a)

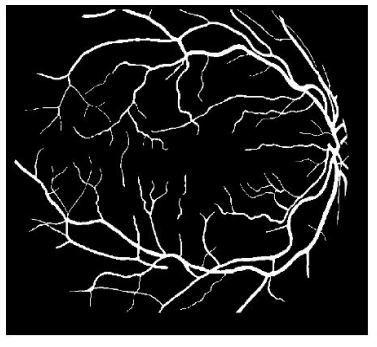

(b)

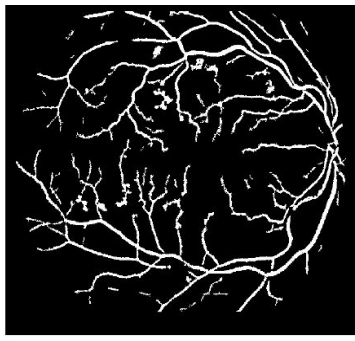

(c)

Fig. 10: Visual segmentation results of an abnormal image of the STARE database. (a) RGB retinal input image (b) Manual segmented image (c) Proposed method final image. 
The AUC acquired from the segmentation results attained by the proposed technique is shown in Table 6 . It shows better AUC results than the previously proposed techniques on the DRIVE and the STARE databases.

Table 6: Performance comparison of AUC with different methods

\begin{tabular}{lcc} 
Method & AUC (DRIVE) & AUC (STARE) \\
\hline Human observer & 0.874 & 0.917 \\
Mendonça and Campilho [25] & 0.855 & 0.836 \\
Martinez-Perez et al. [28] & 0.845 & 0.853 \\
Palomera-Perez et al. [27] & 0.811 & 0.860 \\
Bankhead et al. [30] & 0.837 & 0.854 \\
Fraz et al. [29] & 0.846 & 0.850 \\
Zhao et al. [38] & 0.861 & 0.881 \\
Al-Diri et al. [19] & 0.842 & 0.860 \\
Marin et al. [39] & 0.843 & 0.838 \\
Staal et al. [15] & 0.848 & 0.839 \\
Soares et al. [16] & 0.849 & 0.849 \\
Proposed & $\mathbf{0 . 8 7 6}$ & $\mathbf{0 . 8 6 1}$
\end{tabular}

\section{CONCLUSION}

Precise detection of retinal vessels plays a significant role in the investigation strategy of retinopathy. Some current techniques including supervised and unsupervised, can achieve good segmentation results for wide retinal vessels. However, for thin retinal vessels, these methodologies are unable to recognize them from the background and often lose some vessels connectivity. In this paper, a novel technique is presented for retinal vessel segmentation based on CLAHE and MISODATA. The former is used for contrast enhancement of an image, and the latter is used for retinal vessel detection using global and local thresholding. Postprocessing steps are used to eliminate unconnected pixels.

The proposed framework has been assessed utilizing multiple openly available databases with diverging image resolution. In each case, the proposed framework shows an increase both in sensitivity and accuracy to segment vessels compared to the results from different published papers. Experimental results demonstrated that the presented system can segment both wide and thin vessels accurately, reaching the average accuracy of $95.21 \%$ and $95.69 \%$ on the DRIVE and the STARE databases, respectively. Moreover, the proposed technique is unsupervised, which does not require any manual segmentation for training and also robust for both normal and abnormal images of the both datasets.

\section{REFERENCES}

[1] Gelman R, Elena Martinez-Perez M, Vanderveen DK, Moskowitz A, Fulton AB. (2005) Diagnosis of plus disease in retinopathy of prematurity using Retinal Image multiScale Analysis. Investigative ophthalmology \& visual science, 46(12): 4734-4738.

[2] Bernardes R, Serranho P, Lobo C. (2011) Digital ocular fundus imaging: A review. Ophthalmologica, 226(4): 161-181.

[3] Marius E, Steger S, Sakas G. (2012) Regmentation: A new view of image segmentation and registration. J. Radiation Oncology Informatics, 4(1): 1-23. 
[4] Mohammad Saleh M, Mahloojifar A. (2011) Retinal image analysis using curvelet transform and multistructure elements morphology by reconstruction. IEEE Trans. Biomed. Eng., 58(5):1183-1192.

[5] Kanski JJ, Bowling B. (2012) Synopsis of clinical ophthalmology. Elsevier Health Sciences.

[6] Ying L, Giovanni G, Knighton RW, Lujan BJ, Rosenfeld PJ. (2011) Registration of OCT fundus images with color fundus photographs based on blood vessel ridges. Optics express, 19(1):7-16.

[7] Zwiggelaar R, Astley SM, Boggis CRM, Taylor CJ. (2004) Linear structures in mammographic images: detection and classification. IEEE Trans. Medical Imaging, 23(9):1077-1086.

[8] Shabbir S, Tariq A, Akram MU. (2013). A comparison and evaluation of computerized methods for blood vessel enhancement and segmentation in retinal images. Int. J. Future Comp. Comm., 2(6):600-603.

[9] Muhammad Moazam F, Remagnino P, Hoppe A, Uyyanonvara B, Rudnicka AR, Owen CG, Barman SA. (2012) Blood vessel segmentation methodologies in retinal images-a survey. Comp. Meth. Prog. Biomedicine, 108(1): 407-433.

[10] Azzopardi G, Strisciuglio N, Vento M, Petkov N. (2015) Trainable COSFIRE filters for vessel delineation with application to retinal images. Medical Image Analysis, 19(1):46-57.

[11] Ricci E, Perfetti R. (2007) Retinal blood vessel segmentation using line operators and support vector classification. IEEE Trans. Medical Imaging, 26(10):1357-1365.

[12] Becker C, Rigamonti R, Lepetit V, Fua P. (2013) Supervised feature learning for curvilinear structure segmentation. Medical Image Computing and Computer-Assisted InterventionMICCAI 2013. Springer Berlin Heidelberg, 526-533.

[13] Sinthanayothin C, Boyce JF, Cook HL, Williamson TH. (1999) Automated localisation of the optic disc, fovea, and retinal blood vessels from digital colour fundus images. British J. Ophthal., 83(8):902-910.

[14] Niemeijer M, Staal J, van Ginneken B, Loog M, Abramoff MD. (2004) Comparative study of retinal vessel segmentation methods on a new publicly available database. In Medical Imaging, 648-656. International Society for Optics and Photonics.

[15] Staal J, Abràmoff MD, Niemeijer M, Viergever MA, van Ginneken B. (2004) Ridge-based vessel segmentation in color images of the retina. IEEE Trans. Medical Imaging, 23(4):501509.

[16] Soares JVB, Leandro JJG, Cesar Jr RM, Jelinek HF, Cree MJ. (2006) Retinal vessel segmentation using the 2-D Gabor wavelet and supervised classification. IEEE Trans. Medical Imaging, 25(9):1214-1222.

[17] Lam BSY, Gao Y, Liew AWC. (2010) General retinal vessel segmentation using regularization-based multiconcavity modeling. IEEE Trans. Medical Imaging, 29(7):13691381.

[18] Joshi VS, Reinhardt JM, Garvin MK, Abramoff MD. (2014) Automated method for identification and artery-venous classification of vessel trees in retinal vessel networks. PloS one, 9(2):e88061.

[19] Al-Diri B, Hunter A, Steel D. (2009) An active contour model for segmenting and measuring retinal vessels. IEEE Trans. Medical Imaging, 28(9):1488-1497.

[20] Zhang J, Cui Y, Jiang W, Wang L. (2015) Blood vessel segmentation of retinal images based on neural network. Image and Graphics. Springer International Publishing, 11-17.

[21] Lupaşcu CA, Tegolo D. (2010) Automatic unsupervised segmentation of retinal vessels using self-organizing maps and k-means clustering. Computational Intelligence Methods for Bioinformatics and Biostatistics. Springer Berlin Heidelberg, 263-274.

[22] Chaudhuri S, Chatterjee S, Katz N, Nelson M, Goldbaum M. (1989)"Detection of blood vessels in retinal images using two-dimensional matched filters. IEEE Trans. Medical Imaging, 8(3):263-269.

[23] Hoover A, Kouznetsova V, Goldbaum M. (2000) Locating blood vessels in retinal images by piecewise threshold probing of a matched filter response. IEEE Trans. Medical Imaging, 19(3):203-210. 
[24] Chutatape O, Zheng L, Krishnan SM. (1998) Retinal blood vessel detection and tracking by matched Gaussian and Kalman filters. Engineering in Medicine and Biology Society, Proceedings of the 20th Annual International Conference of the IEEE. vol 6.

[25] Mendonca AM, Campilho A. (2006) Segmentation of retinal blood vessels by combining the detection of centerlines and morphological reconstruction. IEEE Trans. Medical Imaging, 25(9):1200-1213.

[26] Zana F, Klein JC. (2001) Segmentation of vessel-like patterns using mathematical morphology and curvature evaluation. IEEE Trans. Image Processing, 10(7):1010-1019.

[27] Palomera-Pérez MA, Martinez-Perez ME, Benítez-Pérez H, Ortega-Arjona JL. (2010) Parallel multiscale feature extraction and region growing: application in retinal blood vessel detection. IEEE Trans. Inform. Tech. Biomed., 14(2):500-506.

[28] Martinez-Perez ME, Hughes AD, Thom SA, Bharath AA, Parker KH. (2007) Segmentation of blood vessels from red-free and fluorescein retinal images. Med. Image Analysis, 11(1):47-61.

[29] Fraz MM, Barman SA, Remagnino P, Hoppe A, Basit A, Uyyanonvara B, Rudnicka AR, Owen CG. (2012) An approach to localize the retinal blood vessels using bit planes and centerline detection. Comp. Meth. Prog. Biomed., 108(2):600-616.

[30] Bankhead P, Scholfield CN, McGeown JG, Curtis TM. (2012) Fast retinal vessel detection and measurement using wavelets and edge location refinement. PloS one, 7(3): e32435.

[31] Zuiderveld K. (1994) Contrast limited adaptive histogram equalization. Graphics gems IV. Academic Press Professional, Inc., San Diego, CA, USA. 474-485.

[32] Ball GH, Hall DJ. (1965) ISODATA, a novel method of data analysis and pattern classification. Stanford Research Inst., Menlo Park CA.

[33] Gonzalez RC, Woods ER. (2002) Digital image processing. Ed: Prentice Hall Press, Upper Saddle River, New Jersey.

[34] Pizer SM, Amburn EP, Austin JD, Cromartie R, Geselowitz A, Greer T, Romeny B, Zimmerman JB, Zuiderveld K. (1987) Adaptive histogram equalization and its variations. Comp. Vis. Graphics Image Proc., 39(3):355-368.

[35] Pisano ED, Zong S, Hemminger BM, DeLuca M, Johnston RE, Muller K, Braeuning MP, Pizer SM. (1998) Contrast limited adaptive histogram equalization image processing to improve the detection of simulated spiculations in dense mammograms. J. Dig. Imaging, 11(8):193-200.

[36] Staal J, Abramoff MD, Niemeijer M, Viergever MA, van Ginneken B. (2004) DRIVE public online database. [http://www.isi.uu.nl/Research/Databases/DRIVE/].

[37] Hoover and M. Goldbaum. (2000) STARE public online database. [http://www.ces.clemson.edu/ ahoover/stare/].

[38] Zhao Y, Liu Y, Wu X, Harding SP, Zheng Y. (2015) Retinal vessel segmentation: An efficient graph cut approach with retinex and local phase. PloS one, 10(4): e0122332.

[39] Marín D, Aquino A, Gegúndez-Arias ME, Bravo JM. (2011) A new supervised method for blood vessel segmentation in retinal images by using gray-level and moment invariantsbased features. IEEE Trans. Med. Imaging, 30(1):146-158.

[40] Bezdek JC. (1980) A convergence theorem for the fuzzy ISODATA clustering algorithms. IEEE Trans. Pattern Anal. Machine Intel., 1:1-8.

[41] Jain AK, Dubes RC. (1988) Algorithms for clustering data. Prentice-Hall, Inc., Englewood Cliffs, New Jersey. 